\title{
Implementation of Smart Health Care system using Zig-Bee enabled RFID and FPGA Technology
}

\author{
Pranali Patil \\ PG Student (VLSI Design and \\ Embedded Systems) \\ KLE Dr. M. S. Sheshgiri College \\ of Engineering and \\ Technology, Belagavi, India
}

\author{
Udaykumar Naik, PhD \\ Professor (Electronics and \\ Communication) \\ KLE Dr. M. S. Sheshgiri College \\ of Engineering and \\ Technology, Belagavi, India
}

\author{
Vijay Rayar \\ Assistant Professor (Electronics \\ and Communication) \\ KLE Dr. M. S. Sheshgiri College \\ of Engineering and \\ Technology, Belagavi, India
}

\begin{abstract}
In today's healthcare domain Field Programmable Gate Array (FPGA) based platforms using Zig-bee based wireless network helps in medical diagnosis. This paper proposes a simplified real time FPGA system for human physiological purposes. Innovations like the output is observed at the transmitter side on LCD as well as at the receiver side on the display screen id done successfully. In the period of developing population, basic issues in medicinal services framework made the nation some way or the another battling against the wasteful medicinal services. The system provides a simplified testing platform for blood pressure and virtual signal measurements. With the progression of electronic industry, the chip out of date quality is a noteworthy concern. The versatile VLSI configuration is a developing pattern to move from bespoke custom chip based framework to the delicate center processor inserted inside FPGA due to the requesting favourable circumstances like low NRE cost, low time to advertise, less equipment, amazing structure adaptability and reinvent capacity, low power utilization and rapid execution. In electronic industry there are such a significant number of zones, similar to remote interchanges, mechanical autonomy and so forth, where versatile structure has been actualized. In this angle, an endeavour has been made to plan what's more, actualize a propelled human services framework in this article utilizing Zig-bee enabled RFID innovation as per the progressed VLSI plan of the processor. The framework is extremely quick and cost effective obtaining nearly $0 \%$ recognizable identification error. Xilinx ISE 14.3 simulator system has been utilized to simulate the processor module and so as to substantiate our structure we have utilized high performance Spartan 6 FPGA board.
\end{abstract}

\section{Keywords}

RFID, Zig-Bee, Spartan 6 FPGA, Xilinx ISE 14.3, VLSI, Sensors.

\section{INTRODUCTION}

Recent times RFID technology has emerged as power tool in tracking and identification. RFID is effectively utilized in different applications like inventory network the executives to follow things, in war field, military area, in the administration of traffic, following of creatures in woodlands, route of robot etc[1,2,3]. Following gives better coordination and control in such cases. RFID innovation adds higher versatility to the generation [4]. RFIDintroduced ID cards have researched an extraordinary window for Health care framework. RFID utilized in medicinal services framework incorporates social insurance worker or medical staff distinguishing proof card, persistent recognizable proof card, lower leg or wristband ID card and implantable RFID chips.

This project has a keen smart health care unit/ward endeavoured to structure and execute. The system utilizes the Zig-Bee empowered RFID technology. Zig-Bee depends on IEEE 802.15.4, that gives clients a financially efficient standard with capacity to keep running for a considerable length of time on cheap essential batteries for average applications. Zig-Bee gadgets work in unlicensed groups of ISM (Industrial, Scientific, Medical) $2.4 \mathrm{GHz}$ band. The scope of Zig-Bee can be reached out from 10 meters to 75 meters and is subject to the power yield of the gadgets and the inclusion territory. Zig-Bee achieves its engaging low control usage. At the point when a centre point is connected with it passes on and returns to rest mode cutting down the power usage feasibly $[4,5]$. Extra to modified power control inside a predefined domain/zone/ward, the proposed processor will record the patient ID present here, restorative report of each patient and update information, distinguish the ID of authority/support/pro present in this zone and record the arranging as well.

\section{IMPLEMENTATION}

In the transmitter section, Spartan 6 FPGA, Zig-bee module, BP module, RFID module and RFID chips are used. Initially, each patient is provided with a RFID tag, which has a unique ID. The BP is measured through a BP module and it is transmitted to the FPGA. Using RFID module, the RFID tag information is sent to the FPGA. Zig-bee is a transceiver which transmits the data to the FPGA. Finally the result is displayed on the monitor. The FPGA kit also consists of temperature sensor, so that the temperature is also displayed. Now on the display screen, the patient's id, BP and the temperature will be displayed. The block diagram of transmitter is shown in the figure1.

- RFID Module: RFID module is related to EM-18 RFID module. By using this board with FPGA or microcontrollers to read the given card's data is very simple and it requires simple serial connection The board consists of power indicating LED which is red in colour and indicates the detection of card.

- Zig-bee Module: The Zig-bee module used here is CC2500 which is an ease $2.4 \mathrm{GHz}$ handset which is utilized for exceptionally low control remote applications 
- BP Module: The BP measured of the patient is displayed on the FPGA as well as on the display screen of the monitor.

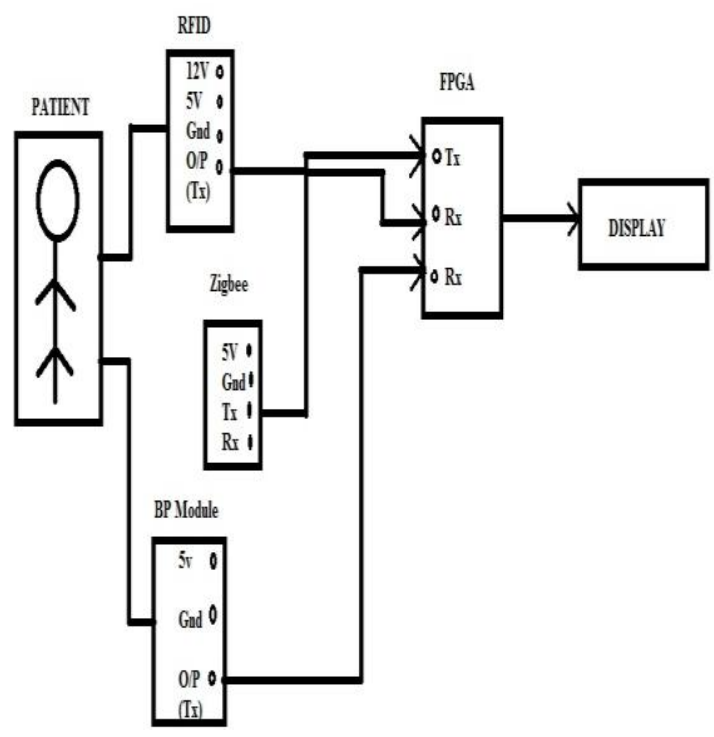

Figure 1: Block diagram of Transmitter.

In the receiver section, UART, Zig-bee module and display monitor is present. As Zig-bee is a transceiver, the data transmitted through the transmitter is received at the receiver by using UART as an interface. The received data will be displayed on the monitor. The block diagram of receiver is shown in the figure 2.

- UART Module: The Zig-bee and UART are interconnected. And finally the UART is connected to the display screen for the display of the output.

The final output displayed on the monitor consists of

i. The patient id.

ii. The blood pressure of the patient.

iii. The room temperature of the ward.

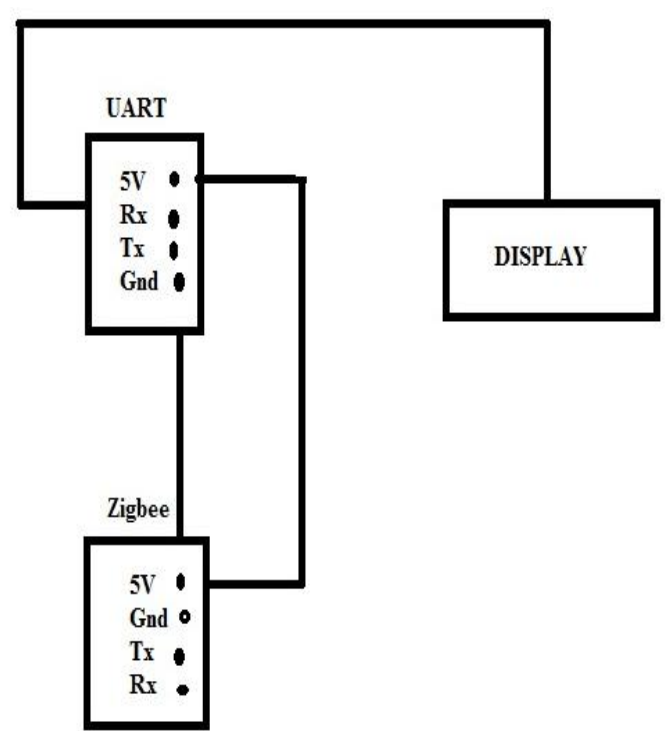

Figure 2: Block diagram of Receiver.

\section{SYSTEM IMPLEMENTATION AND RESULTS}

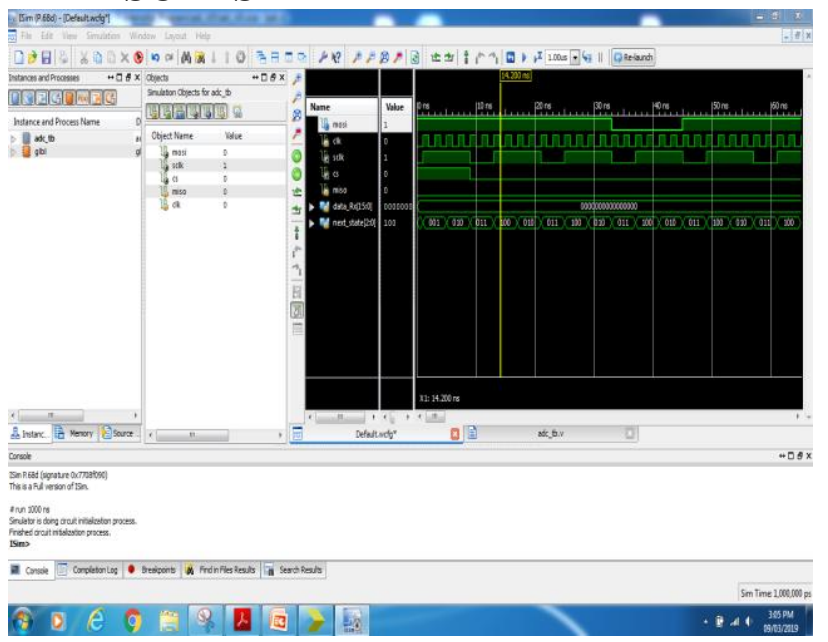

Figure 3: ADC simulation waveform

The above figure represents the waveform of ADC simulation. When the CS is low and CLK is high the following results are obtained.

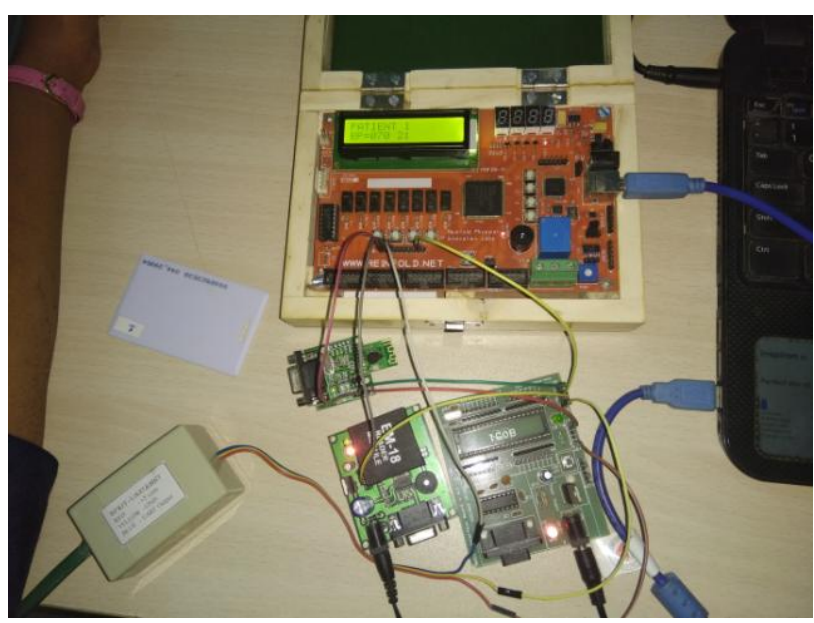

Figure 4: Output of transmitter section of Patient

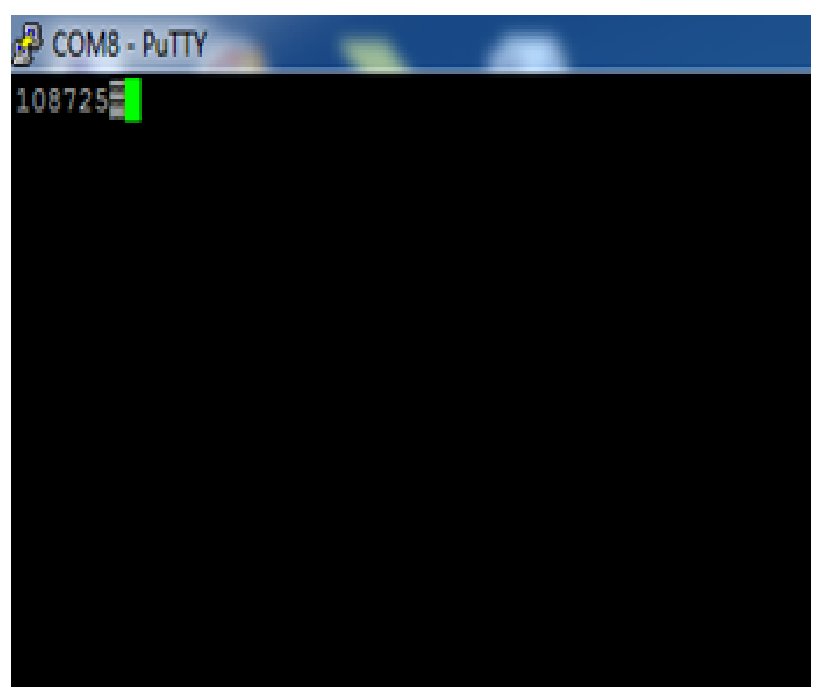

Figure 5: Output at the receiver section of Patient 
The above figure is the output received at the receiver section. The first digit indicates the Patient id, the next three digits indicate the blood pressure of the respective patient and the last two digits indicate the room temperature. Here the patient id is 1 ; the blood pressure of the respective patient is 087 and the room temperature is $25 \mathrm{C}$.

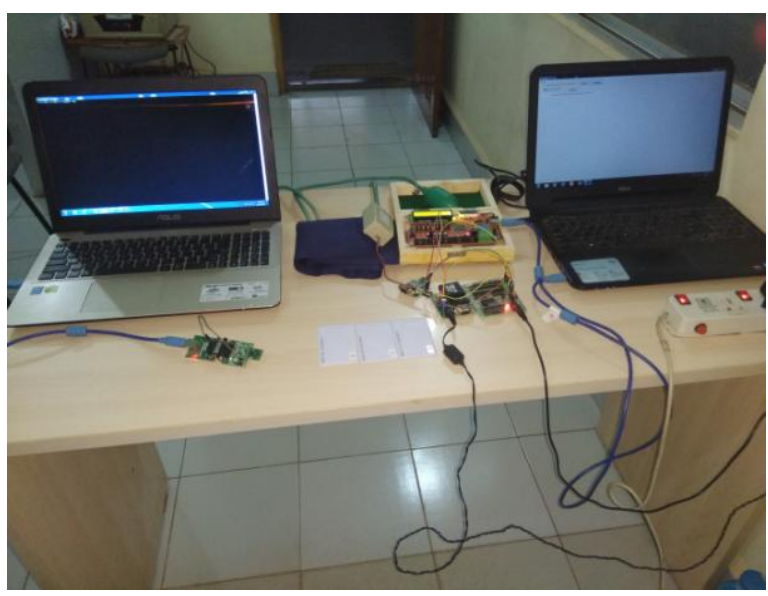

Figure 6: Hardware setup of both transmitter and receiver

\section{SYNTHESIS REPORT}

Simulation result shows desired performance output to clarify the operations of the developed processor. The processor module has been synthesized, implemented successfully.

Advanced HDL Synthesis Report

$\begin{array}{ll}\text { \# Adders/ Subtractors } & : 26 \\ \text { \# Counters } & : 9 \\ \text { \# Registers } & : 265 \\ \text { \# Comparators } & : 29 \\ \text { \# Multiplexers } & : 232\end{array}$

Device utilization summary: Selected Device: 6slx9tqg144-3

Slice Logic Utilization:

Number of Slice Registers: 396 out of 11440 3\%

Number of Slice LUTs: 650 out of $5720 \quad 11 \%$

Number used as Logic: 650 out of $5720 \quad 11 \%$

Slice Logic Distribution:

Number of LUT Flip Flop pairs used: 713

Number with an unused Flip Flop: 317 out of 713 44\%

Number with an unused LUT: 63 out of $7138 \%$

Number of fully used LUT-FF pairs: 333 out of $71346 \%$

Number of unique control sets: 24

IO Utilization:

Number of IOs: 20

Number of bonded IOBs: 20 out of $102 \quad 19 \%$

Specific Feature Utilization:

Number of BUFG/BUFGCTRLs: 4 out of $1625 \%$

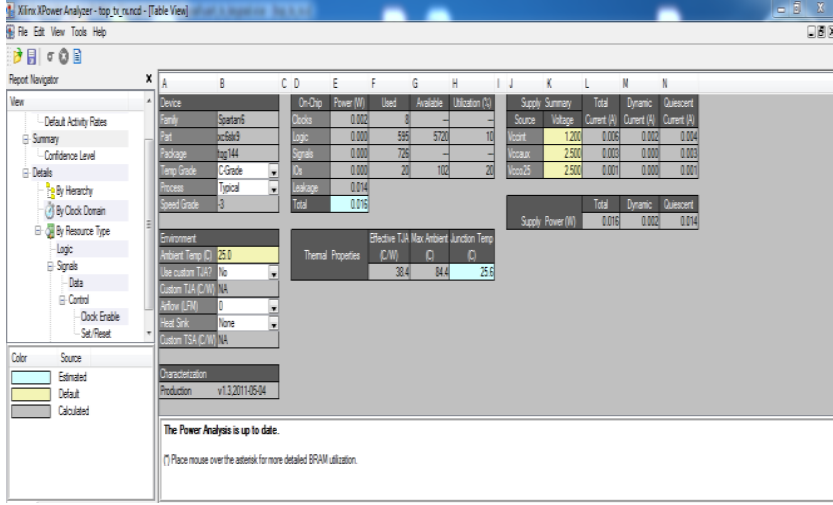

Figure 7: Power Analyzer Report

The total power required is 0.016 Watts.

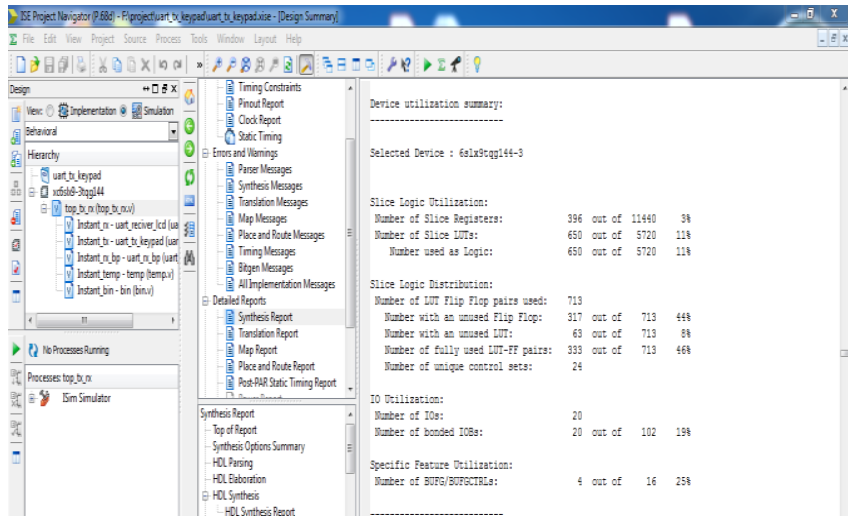

Figure 8: Device Utilization Summary

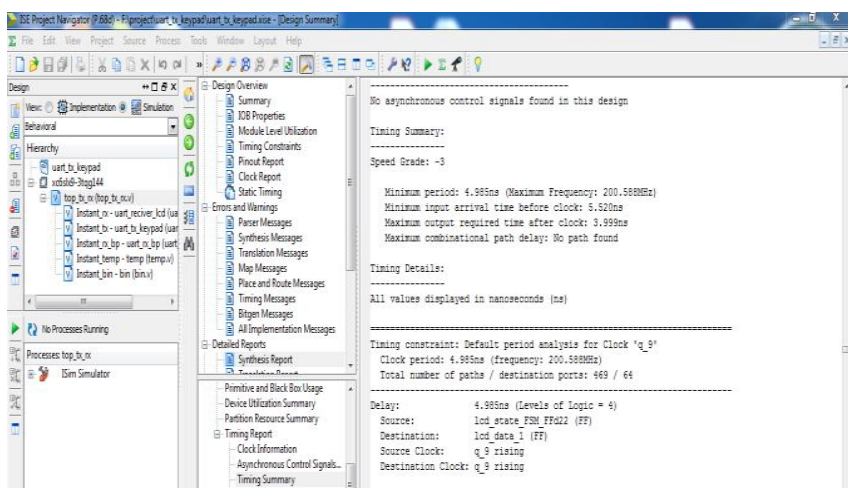

Figure 9: Timing Details Report

\section{CONCLUSION}

The various applications of RFID technology and RFID sensors in the field of medical sciences are well organized and have been driven for a secured health care service system. In this project, an attempt has been made to reduce the burden of the nursing staff by managing the physiological parameters in the real time. It provides a lowcost, fast and efficient diagnostic applications ensuring the health of the patient.

\section{ACKNOWLEDGEMENT}

I want to thank Mr. M N Manjunath and Mrs. Sonali Majukar for giving me an opportunity to work as an internee at Reinfold Physical Innovation Labs. I would also thank the management, Principal, HOD and staff of VLSI and EC Department, K.L.E. Dr.M.S. Sheshgiri College of 
Engineering and Technology, Belagavi, Karnataka, India for encouraging me for this work.

\section{REFERENCES}

[1] Ann Cavoukian, 'RFID and Privacy Guidance for Health-Care Providers' 2008

[2] Sun-Jin Kim, Nae-Su Kim, 'An Approach for Providing Healthcare Services Using RFID Technology in the Korean Market' Proceedings, 9-13 July, Istanbul, Turkey (c) PICMET 2006.pp.1917-1924.

[3] Steele, R., Lo, A., Secombe, C., and Wong, Y. K., 'Elderly persons' perception and acceptance of using wireless sensor networks to assist healthcare'. Int. J. Med. Informat. 78:788-801, 2009.

[4] Chen, C.-M., 'Web-based remote human pulse monitoring system with intelligent data analysis for home health care'. Expert Syst.Appl. 38:pp.2011-2019, 2011.

[5] Lee, S.-Y., Wang, L.-H., and Fang, Q., A low-power RFID integrated circuits for intelligent healthcare systems. IEEE Trans. Inf.Technol. Biomed. 14:pp.1387-1396, 2010

[6] Joyashree Bag, Rajanna K M and Subir Kumar Sarkar, 'Design and FPGA Implementation of Zig-Bee Enabled Processor for RFID reader suitable for power efficient home/office automation', Europeanl Journal of Scientific Research Vol.97, No.4, pp.592-608. March 2013.
[7] ZigBee-Alliance-Website. Available:http://www.zigbee.org.

[8] Lingaraj Duggani, Udaykumar Naik, Vijay Rayar,"VHDL Implementation of Robust WIFI Positioning system", International Journal of Computer applications, 2105,volume 21, number 6 .

[9] Sumi M, Ebrahim Soujeri, Rahim Rajan, Harikrishnan A.I, 'Design of a ZigBee-Based RFID Network for Industry Applications', Proceedings of the 2nd international conference on Security of information and networks.

[10] Tani, S., Marukami, T., Matsuda, A., Shindo, A., Takemoto, K., and Inada, H., 'Development of a healthmanagement support system for patients with diabetes mellitus at home'. J. Med. Syst.34:pp.223-228, 2010.

[11] H S Deepthi ;Sumita Shankar Manure ;Cyril Prasanna Raj P ; Saroja S Bhusare ;U L Naik "Design and FPGA implementation of improved lifting scheme based DWT for OFDM systems", 3rd International Conference on Advances in Recent Technologies in Communication and Computing (ARTCom 2011)Year: 2011 Conference Paper Publisher: IET

[12] Udaykumar Naik; Sameer Hudli ; Prakash Biswagar "A statistical channel model for fixed WiMax in urban residential areas" 2017 2nd IEEE International Conference on Recent Trends in Electronics, Information \& Communication Technology (RTEICT)Year: 2017Conference Paper; Publisher: IEE 